\title{
Synergistic effect of leptin and lipidized PrRP on metabolic pathways in ob/ob mice
}

\author{
Lucia Kořínková1,2, Martina Holubová1, Barbora Neprašová1, Lucie Hrubá1, Veronika Pražienková1, \\ Michal Bencze1,3, Martin Haluzík 2,4, Jaroslav Kuneš1,3, Lenka Maletínská1 and Blanka Železná1 \\ IInstitute of Organic Chemistry and Biochemistry, Academy of Sciences of the Czech Republic, Prague, Czech Republic \\ 2First Faculty of Medicine, Charles University in Prague, Prague, Czech Republic \\ ${ }^{3}$ Institute of Physiology, Academy of Sciences of the Czech Republic, Prague, Czech Republic \\ ${ }_{4}^{4}$ nstitute for Clinical and Experimental Medicine, Prague, Czech Republic
}

Correspondence should be addressed to L Maletínská: maletin@uochb.cas.cz

\begin{abstract}
Lack of leptin production in ob/ob mice results in obesity and prediabetes that could be partly reversed by leptin supplementation. In the hypothalamus, leptin supports the production of prolactin-releasing peptide (PrRP), an anorexigenic neuropeptide synthesized and active in the brain. In our recent studies, the palmitoylated PrRP analog palm ${ }^{11}$-PrRP31 showed a central anorexigenic effect after peripheral administration. This study investigates whether PrRP could compensate for the deficient leptin in ob/ob mice. In two separate experiments, palm ${ }^{11}$-PrRP31 $(5 \mathrm{mg} / \mathrm{kg}$ ) and leptin $(5$ or $10 \mu \mathrm{g} / \mathrm{kg})$ were administered subcutaneously twice daily for 2 or 8 weeks to 8- (younger) or 16-(older) week-old ob/ob mice, respectively, either separately or in combination. The body weight decreasing effect of palm11-PrRP31 in both younger and older ob/ob mice was significantly powered by a subthreshold leptin dose, the combined effect could be then considered synergistic. Leptin and palm ${ }^{11}$-PrRP31 also synergistically lowered liver weight and blood glucose in younger ob/ob mice. Reduced liver weight was linked to decreased mRNA expression of lipogenic enzymes. In the hypothalamus of older ob/ob mice, two main leptin anorexigenic signaling pathways, namely, Janus kinase, signal transducer and activator of transcription-3 activation and AMP-activated protein kinase de-activation, were induced by leptin, palm ${ }^{11}$-PrRP31, and their combination. Thus, palm 11-PrRP31 could partially compensate for leptin deficiency in ob/ob mice. In conclusion, the results demonstrate a synergistic effect of leptin and our lipidized palm¹1-PrRP31 analog.
\end{abstract}
Key Words
- prolactin-releasing peptide
- leptin
- ob/ob mice
- hypothalamic leptin signaling

\section{Introduction}

Leptin has an appetite-regulating effect that occurs in the arcuate nucleus of the hypothalamus, where it activates anorexigenic proopiomelanocortin (POMC) and inhibits orexigenic neuropeptide $\mathrm{Y}$ (NPY) neurons and thus induces a decrease in food intake and an increase in energy consumption (Schwartz et al. 1996, Kwon et al. 2016). In addition, leptin action in the hypothalamus is connected with other anorexigenic neuropeptides, such as prolactin-releasing peptide (PrRP) (Ellacott et al. 2002).

PrRP was described to be produced in the nucleus tractus solitarius (NTS), ventrolateral medulla (VLM), and dorsomedial hypothalamus (DMH) (Maruyama et al. 1999, Dodd \& Luckman 2013). It was suggested that PrRP neurons project from the NTS, where PrRP was detected 
in neuron bodies, to the hypothalamus, where PrRP was found in neuron fibers (Hinuma et al. 1998). In the paraventricular nucleus of the hypothalamus (PVN), PrRP fibers were shown to target anorexigenic corticotropinreleasing hormone (CRH) (Matsumoto et al. 1999). CRH production was also proven to be promoted by leptin (Schwartz et al. 1996).

Most PrRP neurons in VLM and DMH were shown to express leptin receptor (Ellacott et al. 2002); co-localization of PrRP and leptin receptor was questioned in the brainstem (Garfield et al. 2012). The combined central administration of leptin and PrRP had an additive anorexigenic effect on nocturnal food intake in freely fed rats. Moreover, in obese Zucker $f a / f a$ rats lacking functional leptin receptor signaling, negligible PrRP mRNA expression was detected (Ellacott et al. 2002).

Leptin deficiency in $o b / o b$ mice causes obesity based on hyperphagia and decreased energy expenditure; in addition, type 2 diabetes and hyperlipidemia are characteristic of $o b / o b$ mice (Zhang et al. 1994).

Productive binding of leptin to its receptor affects two main anorexigenic pathways in the hypothalamus: JAK-STAT3 signaling (Janus kinase 2, signal transducer and activator of transcription-3) (Vaisse et al. 1996, Maniscalco \& Rinaman 2014) and AMP-activated protein kinase (AMPK) (Minokoshi et al. 2004, Kahn 2019). AMPK is a serine/threonine kinase activated by an increase in the AMP:ATP ratio that reflects energy deficiency (Hardie 2008). In peripheral tissues, leptin-induced activation of AMPK results in lipid oxidation (Minokoshi et al. 2004) and attenuation of stored triglycerides (Unger et al. 1999). On the other hand, inhibition of hypothalamic AMPK is necessary for the anorexigenic and body weight-lowering effects of leptin; leptin inhibits AMPK specifically in the PVN and arcuate nucleus (Arc) of the hypothalamus (Minokoshi et al. 2004).

PrRP-deficient mice displayed late-onset obesity and adiposity, resulting from increased meal size, hyperphagia, and attenuated responses to cholecystokinin and leptin (Takayanagi et al. 2008). As PrRP is a brain-born and brainacting neuropeptide, it cannot be administered peripherally to achieve central anorexigenic effects. Attachment of palmitic acid to PrRP enabled the implementation of the anorexigenic effect of PrRP after peripheral administration and also stabilized the palm ${ }^{11}$-PrRP31 molecule (Maletinska et al. 2015, Prazienkova et al. 2017).

In this study, both leptin and palm ${ }^{11}$-PrRP31 were repeatedly peripherally administered separately or in combination to $o b / o b$ mice to explore the potential interaction between leptin and PrRP regarding their anorexigenic effect and impact on metabolic disturbances in $o b / o b$ mice. If the palm ${ }^{11}$-PrRP31 effect was powered by a subthreshold leptin dose, the combined effect could be considered synergistic. The impact of treatment with leptin, palm11-PrRP31, and their combination on hypothalamic signaling was then investigated to determine whether PrRP followed leptin anorexigenic pathways.

$\mathrm{Ob} / \mathrm{ob}$ mice of two ages were utilized: younger mice (treatment from 8 to 10 weeks old) in a metabolically active state, when the effect of lipidized PrRP on liver lipid metabolism could be expected, as in our previous study with diet-induced obese mice (Maletinska et al. 2015), and older $o b / o b$ mice (treatment from 16 to 24 weeks old) with established morbid obesity.

\section{Materials and methods}

\section{Animals}

$\mathrm{Ob} / \mathrm{ob}$ male mice and their wild-type (WT) littermates (5 weeks old) were obtained from ENVIGO (Correzzana, Italy). The mice were housed under controlled conditions at a constant temperature of $22 \pm 2^{\circ} \mathrm{C}$, a relative humidity of $45-65 \%$ and a fixed daylight cycle (lights on: 6:00 $\mathrm{h}-18: 00 \mathrm{~h}$ ), with two mice per cage. The animals were provided free access to water and the standard rodent chow diet Ssniff ${ }^{\circledR}$ R/M-H (Ssniff Spezialdiäten GmbH, Soest, Germany) containing 33, 9 and 58\% of calories from proteins, fats and carbohydrates, respectively.

All of the animal experiments followed the ethical guidelines for animal experiments and the Act of the Czech Republic Nr. 246/1992 and were approved by the Committee for Experiments with Laboratory Animals of the Academy of Sciences of the Czech Republic.

\section{Substances}

Palm ${ }^{11}$-PrRP31, an analog of human prolactin-releasing peptide palmitoylated at position 11, was synthesized at the Institute of Organic Chemistry and Biochemistry, Czech Academy of Sciences, Prague, Czech Republic, as previously described (Pražienková et al. 2017). The structure of palm ${ }^{11}$-PrRP31 was SRTHRHSMEIK(N- $\gamma$-E(Npalmitoyl)) TPDINPAWYASRGIRPVGRF-NH2. Mouse leptin was obtained from Sigma-Aldrich.

\section{Dosing of substances}

Leptin doses (5 and $10 \mu \mathrm{g} / \mathrm{kg}$ twice daily) were chosen as a subthreshold according to a daily dose of $1 \mu \mathrm{g} /$ mouse that was proven to be the minimum to achieve the anorexigenic 
effect in $o b / o b$ mice (Harris et al. 1998). The palm ${ }^{11}$-PrRP31 dose used ( $5 \mathrm{mg} / \mathrm{kg}$ twice daily) was chosen according to our previous studies, where it consistently decreased food intake in lean C57BL/6J mice after acute administration and food intake and body weight in C57BL/6J mice with diet-induced obesity after sub chronic administration (Prazienkova et al. 2017, Holubova et al. 2018).

\section{Experimental design}

The schema of the experimental design is shown in Fig. 1.

In Experiment 1,ob/ob and WT male mice (5 weeks old) were randomized into groups of 8-10 animals. After 8 weeks of age (younger mice), the mice were treated for 2 weeks as follows: 1 . WT saline, 2. ob/ob saline, 3. ob/ob leptin, $(5 \mu \mathrm{g} / \mathrm{kg})$, 4. ob/ob palm ${ }^{11}-\operatorname{PrRP} 31(5 \mathrm{mg} / \mathrm{kg})$, and 5. $o b / o b$ leptin +palm ${ }^{11}-\operatorname{PrRP}(5 \mu \mathrm{g} / \mathrm{kg}+5 \mathrm{mg} / \mathrm{kg})$. The compounds were dissolved in saline and administered subcutaneously twice a day. Food intake (FI) and body weight (BW) were monitored daily during the dosing period.

In Experiment 2, ob/ob and WT male mice (6-8 weeks old) were randomized into groups of ten animals. After 16 weeks of age (older mice), the mice were treated for 8 weeks as follows: 1 . WT saline, 2. ob/ob saline, 3. ob/ob leptin $(10 \mu \mathrm{g} / \mathrm{kg})$, 4. ob/ob palm ${ }^{11}$-PrRP31 $(5 \mathrm{mg} / \mathrm{kg})$, and 5. $o b / o b$ leptin + palm ${ }^{11}-\operatorname{PrRP}(10 \mu \mathrm{g} / \mathrm{kg}+5 \mathrm{mg} / \mathrm{kg})$.

The compounds were dissolved in saline and administered subcutaneously twice a day. FI and BW were monitored daily during the dosing period.

The oral glucose tolerance test (OGTT) was measured in Experiment 2 (Fig. 1): 6-h-fasted mice were administered a glucose solution at a dose of $2 \mathrm{~g} / \mathrm{kg}$ BW by gavage. Blood samples were obtained from the tail vessels. The blood glucose concentrations were measured using a glucometer (Arkray, Tokyo, Japan) at 0, 30, 60, 90, 120, and $180 \mathrm{~min}$ after glucose administration.

In the open field test in Experiment 2, fed mice were placed individually in an open field (TSE Systems,
Bad Homburg, Germany), and their locomotor activity (velocity, total distance traveled, percentage of area visited and distance from the closest wall) was measured as described previously (Maletínská et al. 2008, 2015).

One week before the end of both experiments, rectal temperature was measured (Rodent thermometer BIO-TK9882, Bioseb, Pinellas Park, FL, USA).

At the end of both experiments, blood samples were collected from the tail veins of 12-h fasted mice, and blood plasma was separated and stored at $-80^{\circ} \mathrm{C}$. The mice were then deeply anesthetized with pentobarbital (170 $\mathrm{mg} / \mathrm{kg}$ of body weight, Sigma-Aldrich) and transcardially perfused with ice-cold $0.01 \mathrm{~mol} / \mathrm{L} \mathrm{pH} 7.4$ phosphate buffered saline (PBS) supplemented with heparin (10 U/mL, Zentiva, Prague, Czech Republic). The brains were removed, and the hypothalami were dissected and lysed in lysis buffer (Špolcová et al. 2015). During the dissections, the brains were maintained on ice to prevent tissue degradation. Subcutaneous adipose tissue (SCAT), intraperitoneal adipose tissue (IPAT) and livers of all of the mice were dissected and weighed. The liver was dissected, and the caudate lobes of each liver were fixed in $4 \%$ paraformaldehyde in $0.1 \mathrm{~mol} / \mathrm{L}$ phosphate buffer at $\mathrm{pH}$ 7.4. After $24 \mathrm{~h}$ of fixation, the liver was stored in $70 \%$ ethanol at $4^{\circ} \mathrm{C}$ until tissue processing in the Leica ASP200S tissue processor (Leica Biosystems Inc.). The paraffin embedding station Leica EG1150H (Leica Biosystems Inc.) was used to create paraffin blocks from the wax-penetrated liver samples. Another part of liver tissue, IPAT and SCAT were flash-frozen in liquid nitrogen and stored at $-80^{\circ} \mathrm{C}$ for later extraction of mRNA.

\section{Determination of hormonal and biochemical parameters}

The blood glucose levels were measured using a glucometer (Arkray, Kyoto, Japan). Glycated hemoglobin (HbA1c) was measured using Afinion kits (Afinion AS100, Axis-Shield PoC-AS, Oslo, Norway). The plasma insulin concentrations

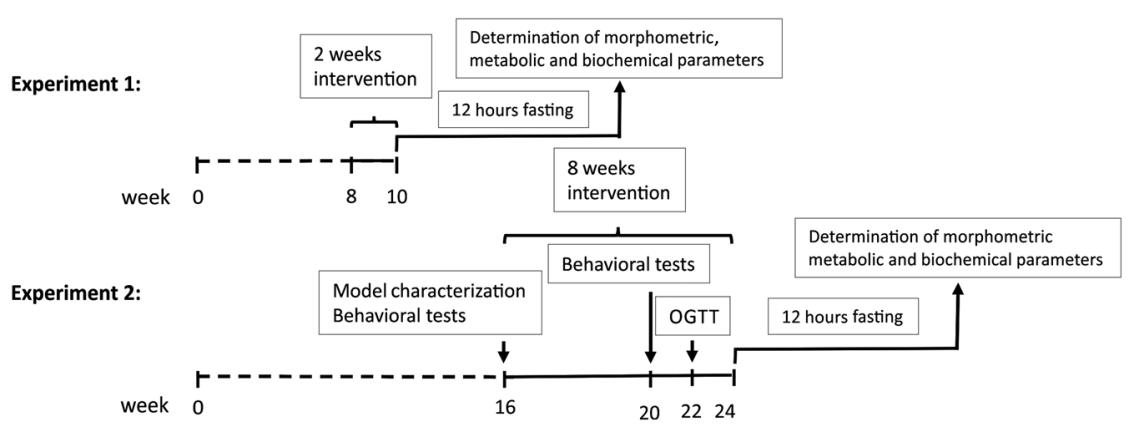

Figure 1

Schema of experimental design. https://jme.bioscientifica.com

https://doi.org/10.1530/JME-19-0188 (c) 2020 Society for Endocrinology Published by Bioscientifica Ltd. Printed in Great Britain 
were measured using an RIA assay (Millipore). Cholesterol was determined by colorimetric assay (Erba Lachema, Brno, Czech Republic). The plasma triglyceride (TAG) levels were measured using a quantitative enzymatic reaction (Sigma-Aldrich), and the free fatty acid (FFA) levels were determined using a colorimetric assay (Roche). All measurements were performed according to the manufacturer's instructions.

\section{Liver histology}

Liver samples in paraffin blocks were cut on a Leica RM2255 microtome (Leica Biosystems Inc.) to slices of 5 $\mu \mathrm{m}$ thickness. Deparaffinization in xylene and rehydration in an ethanol range was performed. Slices were stained in hematoxylin using Weigert's iron hematoxylin solution set (HT1079-1Set, Sigma-Aldrich). Slices were washed with tap water and subsequently stained for $1 \mathrm{~min}$ in $0.5 \%$ eosin Y (C.I. 45380, Carl Roth GmbH + Co. KG, Karlsruhe, Germany). After washing with tap water, the samples were dehydrated and covered with DPX mounting medium (06522, Sigma-Aldrich). Histological images were performed at $200 \times$ magnification.

\section{Western blotting}

Hypothalami were processed, and Western blotting was performed as previously described (Špolcová et al. 2015). The following primary antibodies were used: total STAT3, phospho-STAT3 (Y705), phospho-STAT3 (S727), SOCS3, total AMPK, phospho-AMPK, phosphoinositide-3kinase (PI3 kinase), total AKT, phospho-AKT (S473) (Cell Signaling Technology) and beta-actin (Sigma-Aldrich). The following secondary antibodies were used: antimouse IgG HRP-linked antibody and anti-rabbit IgG HRPlinked antibody (Cell Signaling Technology).

\section{Determination of mRNA expression}

The mRNA expression of the genes of interest in liver (acetyl-CoA carboxylase 1 (Acaca), peroxisome proliferatoractivated receptor (Prarg and Ppara), sterol regulatory element-binding protein 1 (Srepf1), fatty acid synthase (Fasn), phosphoenolpyruvate carboxykinase 1 (Pck1), carnitine palmitoyltransferase 1a (Cpt1a), and glucose-6phosphatase $(G 6 p c)$ ) was determined using an ABI PRISM 7500 instrument (Applied Biosystems) in samples from the mouse liver as described previously (Prazienkova et al. 2017). The expression of beta-2-microglobulin (B2m) was used to compensate for variations in input mRNA amounts and the efficiency of RT. The formula 2-dCt was used to calculate relative gene expression.

\section{Statistics}

The data are presented as the means \pm S.E.M. Statistical analysis was performed using unpaired $t$-test or one-way or two-way ANOVA followed by Bonferroni's post hoc test as indicated in Figure legends and Tables with Graph-Pad Prism Software, and $P<0.05$ was considered statistically significant.

\section{Results}

Experiment 1: Treatment with leptin, palm ${ }^{11}$-PrRP31, and their combination in younger ob/ob mice

The leptin + palm ${ }^{11-P r R P 31}$ combination attenuated food intake and body weight in a synergistic manner in younger mice

A decreasing effect of the leptin+palm ${ }^{11}$-PrRP31 combination on cumulative food intake was significant after the first day of treatment compared to both the $o b / o b$ saline and $o b / o b$ leptin; between days 11 and 14, the effect of the combined treatment was significant compared to that in the $o b / o b$ saline. There were significant differences between phenotypes (ob/ob saline versus WT saline) between days 5 and 14. (Fig. $2 \mathrm{~A}$ and B). The body weight change caused by the treatment was significant only for the leptin+palm ${ }^{11}$-PrRP31 combination since day 12 compared to both $o b / o b$ saline and $o b / o b$ leptin (Fig. 2C); it was obvious that $o b / o b$ mice did not gain weight during the treatment with the leptin+palm ${ }^{11}$ PrRP31 combination. The final body weight of $o b / o b$ saline was significantly higher than that of WT saline (Fig. 2D); only the leptin + palm ${ }^{11}$-PrRP31 combination significantly lowered the final body weight compared to $o b / o b$ saline (Fig. 2E).

\section{Leptin and palm ${ }^{11}$-PrRP31 synergistically decreased the liver weight of younger ob/ob mice}

As expected, WT saline group had significantly lower weights of SCAT and IPAT compared to $o b / o b$ saline group. None of the treatments affected adipose tissue weights compared to $o b / o b$ saline (Table $1 \mathrm{~A}$ ).

The liver weight of WT saline group was significantly higher than that of $o b / o b$ saline group (Fig. 3A and Table 1A). Leptin significantly lowered liver weight in $o b / o b$ 
A

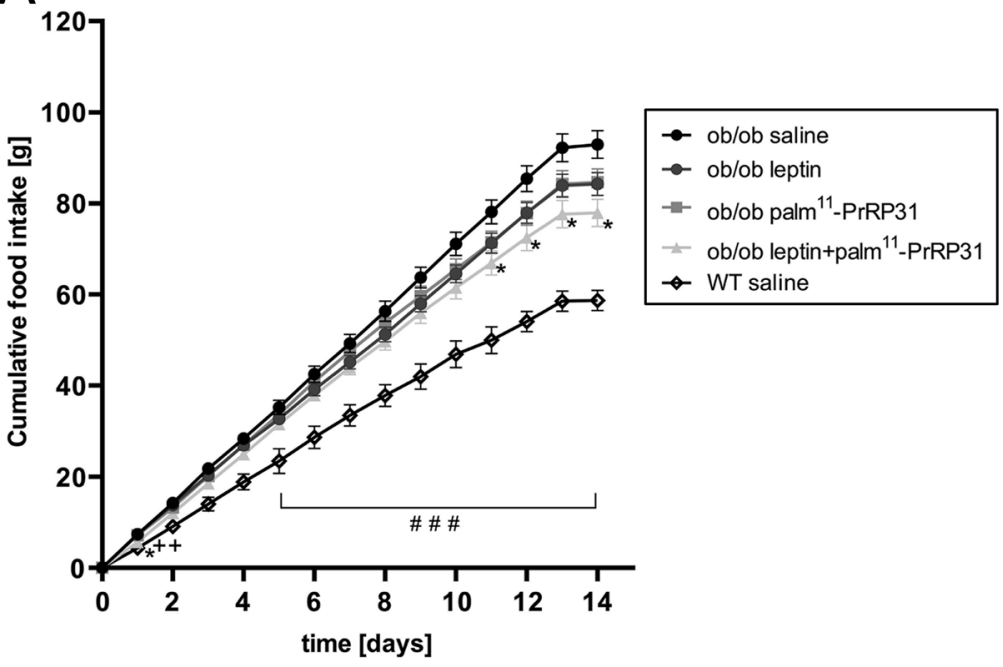

B

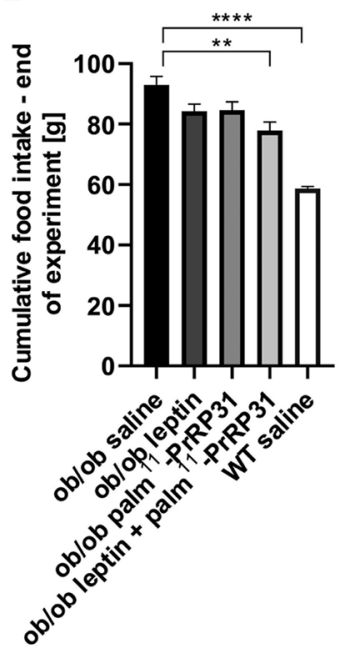

C

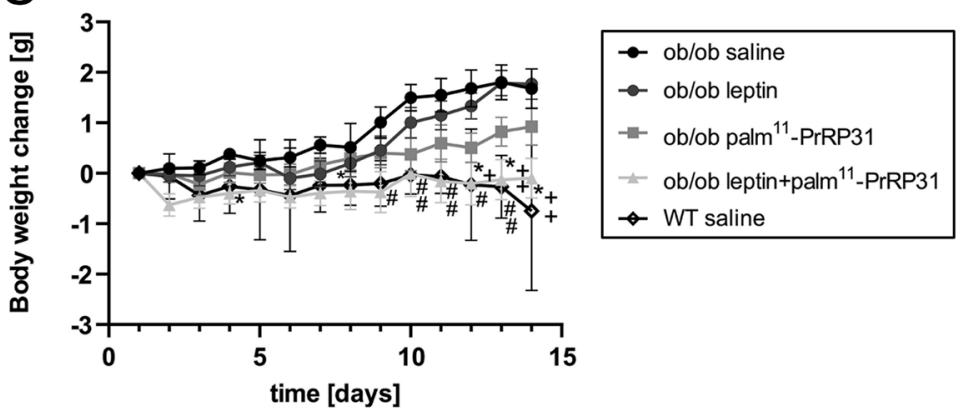

D

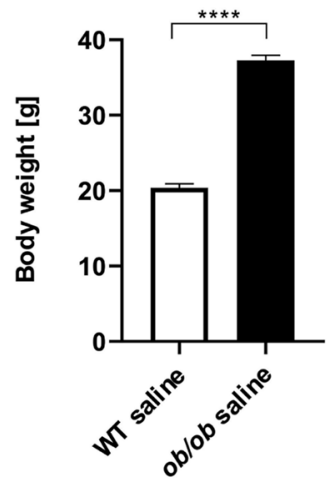

E

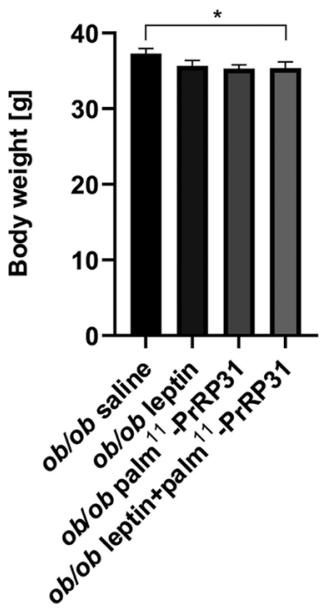

Figure 2

Food intake and body weight change of ob/ob mice in Experiment 1. (A) Food intake and (B) cumulative food intake at the end of experiment: ob/ob mice treated with saline, leptin, palm11-PrRP31 and leptin + palm ${ }^{11}$-PrRP31. (C) Body weight change of ob/ob mice treated with saline, leptin, palm ${ }^{11}$-PrRP31 and leptin + palm 11-PrRP31. (D) Body weight at the end of experiment of WT saline and ob/ob saline mice. (E) Body weight at the end of experiment of $o b / o b$ treated mice with saline, leptin, palm ${ }^{11}$-PrRP31 and leptin + palm ${ }^{11}$-PrRP31. Data are means \pm S.E.M. $(n=8-10)$. Significance is ${ }^{* /+} P<0.05, * \star /++P<0.01$, $* \star \star * /++++P<0.0001$ vs ob/ob saline or ob/ob leptin group, respectively (t-test or one-way ANOVA + Bonferroni post hoc test). Magnification was 200 $\times$.

mice; its effect was pronounced in the leptin + palm ${ }^{11}$ PrRP31 combination (Fig. 3A and Table 1A). As single leptin did not cause any significant effect, the combined action of leptin and palm11-PrRP31 seems synergistic (Fig. 3B). Histology of liver slices demonstrated regression of fat droplets in the liver tissue of all treated $o b / o b$ groups compared to $o b / o b$ saline toward the image of WT saline (Fig. 3C).

Body temperature was significantly lower in $o b / o b$ saline compared to WT saline; none of the treatments affected body temperature in $o b / o b$ mice (Table $1 \mathrm{~A}$ ).

\section{Leptin and palm ${ }^{11-P r R P 31}$ synergistically attenuated blood glucose in younger ob/ob mice}

Hyperglycemia was obvious in $o b / o b$ saline compared to WT saline (Table 1B). Blood glucose was significantly lowered by both leptin and palm11-PrRP31, and the leptin + palm ${ }^{11}$-PrRP31 combination normalized glycemia to the level of WT saline (Table 1B); this result again pointed to a synergistic action of leptin and palm ${ }^{11}$-PrRP31. Ob/ob saline was very significantly hyperinsulinemic compared to WT saline (Table 1B); neither treatment significantly affected the insulin level of $o b / o b$ mice (Table 1B). 
Table 1 Morphometric and metabolic parameters in Experiment 1.

\begin{tabular}{|c|c|c|c|c|c|}
\hline & WT saline & ob/ob saline & ob/ob leptin & $\begin{array}{l}\text { ob/ob palm }{ }^{11}- \\
\text { PrRP31 }\end{array}$ & $\begin{array}{c}\text { ob/ob leptin+palm 11- } \\
\text { PrRP31 }\end{array}$ \\
\hline \multicolumn{6}{|c|}{ (A) Morphometric parameters } \\
\hline BW (g) & 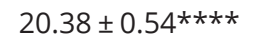 & $37.28 \pm 0.67$ & $35.64 \pm 0.75$ & $35.30 \pm 0.49$ & $35.34 \pm 0.85$ \\
\hline $\operatorname{SCAT}(g)$ & $0.28 \pm 0.05^{\star \star \star *}$ & $4.08 \pm 0.28$ & $3.74 \pm 0.28$ & $3.60 \pm 0.29$ & $3.68 \pm 0.24$ \\
\hline IPAT $(g)$ & $0.28 \pm 0.04 * * * \star$ & $2.83 \pm 0.11$ & $2.57 \pm 0.09$ & $2.51 \pm 0.10$ & $2.60 \pm 0.10$ \\
\hline Liver weight (g) & $0.97 \pm 0.24 * \star \star *$ & $2.73 \pm 0.11$ & $2.36 \pm 0.09 *$ & $2.36 \pm 0.12$ & $2.08 \pm 0.09 * * *$ \\
\hline Rectal temp $\left({ }^{\circ} \mathrm{C}\right)$ & $36.75 \pm 0.17 * \star \star \star$ & $35.00 \pm 0.21$ & $35.64 \pm 0.28$ & $35.22 \pm 0.32$ & $35.33 \pm 0.36$ \\
\hline \multicolumn{6}{|c|}{ (B) Metabolic parameters } \\
\hline Glucose $(\mathrm{mmol} / \mathrm{l})$ & $5.65 \pm 0.18 * * *$ & $14.19 \pm 1.82$ & $9.38 \pm 1.16^{*}$ & $9.71 \pm 1.21$ * & $5.97 \pm 0.35^{* * *}$ \\
\hline Insulin (ng/ml) & $1.47 \pm 0.51 * * * *$ & $21.02 \pm 3.53$ & $15.35 \pm 3.34$ & $24.03 \pm 4.41$ & $19.27 \pm 3.06$ \\
\hline $\mathrm{CHOL}(\mathrm{mmol} / \mathrm{l})$ & $2.07 \pm 0.10 * * *$ & $3.43 \pm 0.22$ & $3.13 \pm 0.10$ & $3.18 \pm 0.21$ & $3.11 \pm 0.12$ \\
\hline TAG $(\mathrm{mmol} / \mathrm{l})$ & $1.02 \pm 0.12$ & $0.90 \pm 0.09$ & $1.02 \pm 0.07$ & $0.79 \pm 0.04$ & $1.11 \pm 0.08$ \\
\hline FFA (mmol/l) & $0.12 \pm 0.01 * * *$ & $0.32 \pm 0.04$ & $0.39 \pm 0.05$ & $0.34 \pm 0.07$ & $0.46 \pm 0.04$ \\
\hline
\end{tabular}

(A) Morphometric parameters of WT saline and ob/ob mice treated with saline, leptin, palm¹1-PrRP31 and leptin + palm ${ }^{11}$-PrRP31. (B) Metabolic parameters of WT saline and ob/ob mice treated with saline, leptin, palm ${ }^{11}$-PrRP31 and leptin + palm ${ }^{11}$-PrRP31. Data are means \pm s.E.M. $(n=8-10)$. Significance is $* P<0.05$, $* * P<0.01, * * * P<0.001$ vs ob/ob saline (t-test or one-way ANOVA + Bonferroni post hoc test).

Increased cholesterol but comparable TAG and FFA levels were detected in $o b / o b$ saline compared to WT mice. None of the treatments affected cholesterol or TAG or FFA levels in $o b / o b$ mice (Table 1B).

\section{The leptin + palm11-PrRP31 combination lowered liver mRNA expression of enzymes regulating lipid metabolism in younger mice}

Liver mRNA expression levels of Acaca (Fig. 4A), which catalyzes the rate-limiting step in fatty acid synthesis, and Fasn (Fig. 4B), which catalyzes the next step of de novo lipogenesis, were higher in $o b / o b$ saline than those in WT saline and were attenuated similarly by the treatment with the leptin + palm ${ }^{11}$-PrRP31 combination (Fig. 4A and B). Single leptin treatment also lowered Fasn mRNA liver expression in $o b / o b$ mice (Fig. 4B). However, no difference in the mRNA expression of Srebf1, which controls the expression of Acaca and Fasn, was found between the $o b / o b$ saline and WT saline groups, and no treatment affected it significantly (Fig. 4C). The mRNA expression levels of Pck1 and Cpt1a, both enzymes regulating fatty acid oxidation, were also significantly enhanced in $o b / o b$ saline compared to WT saline, but no treatment affected their expression (Fig. 4D and E). A similar pattern was observed for peroxisome proliferator-activated receptors Ppara and Pparg, which are other regulators of fatty acid oxidation (Fig. 4F and G).

The mRNA expression of $G 6 p c$, a key enzyme catalyzing gluconeogenesis and glycogenolysis, was enhanced in the $o b / o b$ saline compared to WT saline and was attenuated by leptin + palm ${ }^{11}$-PrRP31 combination treatment (Fig. 4H).

Ucp-1 mRNA expression was determined in Experiment 1. There were no significant differences (Supplementary
Fig. 4A, see section on supplementary materials given at the end of this article).

Experiment 2: Treatment with leptin, palm ${ }^{11-}$ PrRP31, and their combination in older ob/ob mice

\section{Treatment did not affect the behavior of older ob/} ob mice

The open field test clearly showed lowered velocity, traveled distance and area covered by 16-week-old $o b / o b$ mice compared to the age-matched WT mice. Analogously, after treatment at the age of $16-24$ weeks, $o b / o b$ saline showed a significant decrease in all of the above-mentioned parameters, and no effect of treatment on locomotor activity was found. Since the average distance from the maze wall (wall distance) did not differ between $o b / o b$ mice and WT mice at either 16 or 24 weeks, we could assume that anxiety was not a probable cause of locomotor activity attenuation (Supplementary Fig. 1). The lower mobility could be attributed to the morbid obesity of $o b / o b$ mice and leptin deficiency-related behavioral changes.

\section{Morphometric and metabolic parameters before the treatment of older mice}

Before starting the experiment, at the age of 16 weeks, ten $o b / o b$ and ten WT mice were taken out from their particular cohort to characterize them before the treatment. Body, SCAT, and liver weights were significantly lower in WT mice compared to $o b / o b$ mice (Supplementary Table 1A).

Analogously to Experiment 1, ob/ob mice had high hyperinsulinemia, but unlike in Experiment 1, they were normoglycemic similarly as WT mice (Supplementary Table 1B). Similar to Experiment 1,ob/ob mice had a significantly 
A
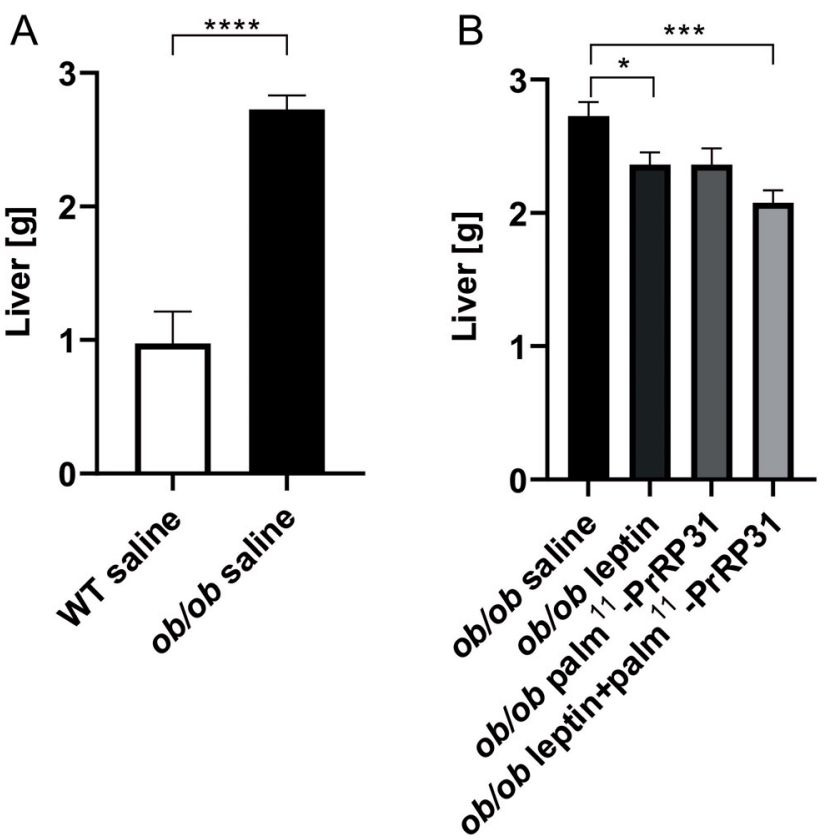

C

WT saline

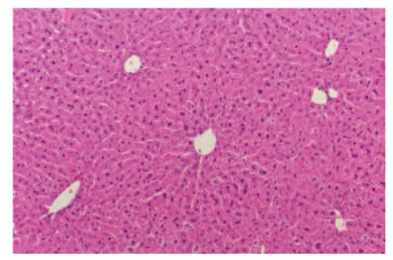

$o b / o b$ leptin

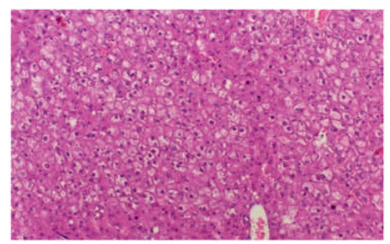

ob/obleptin + palm $11-$ PrRP31

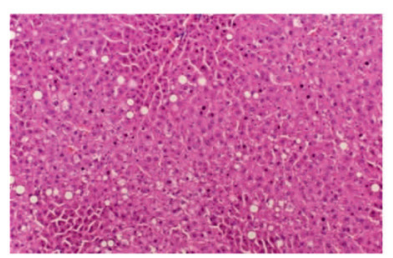

Figure 3

Liver weight and liver histology of ob/ob mice in Experiment 1. (A) Liver weight of WT saline and $o b / o b$ saline mice. (B) Liver weight of ob/ob mice treated with saline, leptin, palm¹1-PrRP31 and leptin + palm ${ }^{11}$-PrRP31. (C) Liver histology of WT saline, ob/ob saline, ob/ob leptin, ob/ob palm ${ }^{11}$ PrRP31 and ob/ob leptin + palm ${ }^{11}$-PrRP31. Data are means \pm S.E.M. $(n=8-10)$. Significance is $* /+P<0.05, * \star \star /+++P<0.001, * \star \star \star /++++P<0.0001$ vs $o b / o b$ saline or ob/ob leptin group, respectively ( $t$-test or one-way ANOVA + Bonferroni post hoc test). increased cholesterol level, but TAG and FFA levels did not differ from those of WT mice (Supplementary Table 1B).

\section{Leptin and palm ${ }^{11-P r R P 31 ~ s y n e r g i s t i c a l l y ~ l o w e r e d ~}$ body weight in older ob/ob mice}

None of the treatments affected cumulative food intake compared to $o b / o b$ saline (Fig. 5A and B). Until day 22 of the treatment, the leptin + palm ${ }^{11}$-PrRP31 combination caused a negative change in body weight in $o b / o b$ mice (Fig. 5C). The change in body weight caused by the leptin + palm ${ }^{11}$. PrRP31 combination was significant compared to that of the $o b / o b$ saline after day 20 and compared to that of $o b / o b$ leptin after day 22 of the treatment (Fig. 5C). Figure 5C showed a decline in body weight at day 20, this could happen because anorexigenic substances in mice with DIO were effective until certain time of the treatment and then the effect of the substance ceased most probably because of the compensatory mechanisms that attenuated anorexigenic effect of the substances. This is also known from the treatment of obesity in humans as well. The final body weight of $o b / o b$ saline was significantly higher than that of WT saline (Fig. 5D); treatment with the leptin+palm ${ }^{11}$-PrRP31 combination lowered the final body weight significantly compared to $o b / o b$ saline (Fig. $5 \mathrm{E})$. All results point to a synergistic effect of leptin and palm ${ }^{11}$-PrRP31 on body weight in $o b / o b$ mice.

\section{Leptin and palm ${ }^{11-P r R P 31 ~ n o r m a l i z e d ~ b o d y ~}$ temperature synergistically in older ob/ob mice}

As expected, SCAT weight was significantly higher in $o b / o b$ saline compared to WT saline. Only leptin + palm ${ }^{11}$-PrRP31 significantly lowered SCAT weight (Table 2A). Similar to Experiment 1, WT saline group had a significantly lower liver weight than $o b / o b$ mice. Unlike Experiment 1, no treatment significantly affected the liver weight of $o b / o b$ mice (Table 2A).

Similar to Experiment 1, ob/ob saline were hypothermic compared to WT saline. Although single leptin and single palm ${ }^{11}$-PrRP31 did not affect body temperature, the leptin + palm ${ }^{11}$-PrRP31 combination significantly upregulated the body temperature of $o b / o b$ mice (Table $2 \mathrm{~A}$ ); these findings again could point to their synergistic action.

\section{The treatment did not affect glucose resistance but lowered cholesterol in older ob/ob mice}

The glucose level in $o b / o b$ saline did not differ from the normoglycemic WT saline; no treatment affected blood 

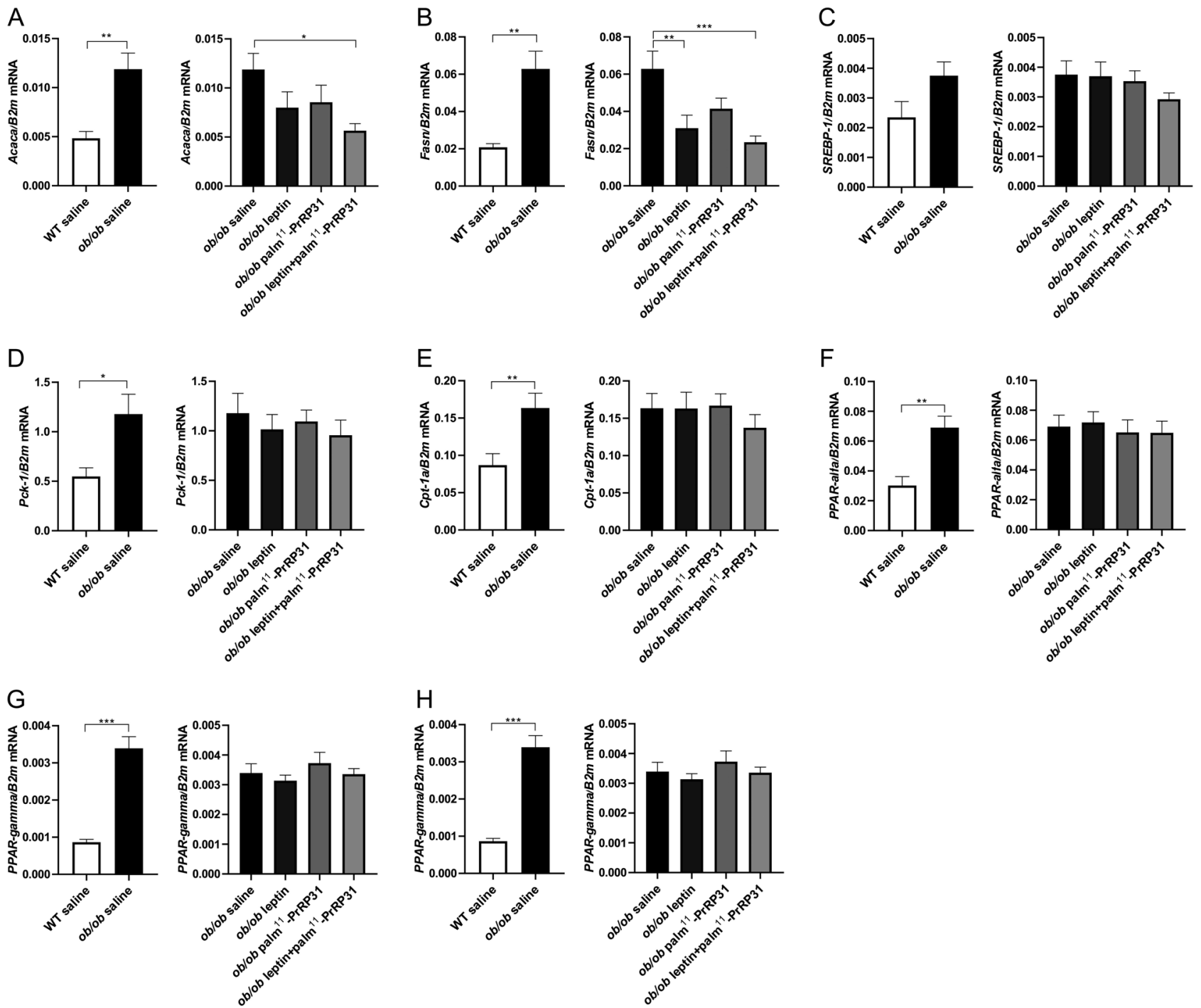

Figure 4

mRNA expression in liver in Experiment 1. Ob/ob mice were treated with saline, leptin, palm ${ }^{11}$-PrRP31 and leptin + palm ${ }^{11}$-PrRP31. (A) Acaca. (B) Fasn. (C) Srebf1. (D) Pck1. (E) Cpt1a. (F) Ppara. (G) Pparg. (H) G6pc. Data are means \pm S.E.M. $(n=8-10)$. Significance is $* P<0.05, \star \star P<0.01, \star \star \star P<0.001$ vs ob/ob saline ( $t$-test or one-way ANOVA + Bonferroni post hoc test).

glucose measured at the end of Experiment 2 (Table 2B). On the other hand, the $o b / o b$ saline had significantly higher HbA1c levels compared to WT saline; no treatment affected HbA1c levels (Table 2B). The course of OGTT was similar for all treated and $o b / o b$ saline, and compared to that of WT mice, it pointed to glucose intolerance in $o b / o b$ mice untreatable by leptin and PrRP analog at doses used (Fig. 6). Again, $o b / o b$ mice were hyperinsulinemic compared to WT mice (Table 2B).

Similar to Experiment 1, cholesterol levels were significantly higher in $o b / o b$ saline than in WT saline at the end of Experiment 2. Unlike Experiment 1, treatment with palm ${ }^{11}$-PrRP31 and its combination with leptin attenuated cholesterol levels toward that of WT saline (Table 2B). The TAG and FFA levels did not differ between $o b / o b$ saline and WT saline; neither were affected by any treatment (Table $2 \mathrm{~B})$.

\section{Liver mRNA expression of proteins regulating lipid metabolism was not affected by the treatment in older ob/ob mice}

Unlike Experiment 1, no difference was found in liver mRNA expression of enzymes and transcription factors regulating lipid metabolism between $o b / o b$ saline and WT saline, and no treatment affected these mRNA liver expression levels (Supplementary Fig. 2). 
A

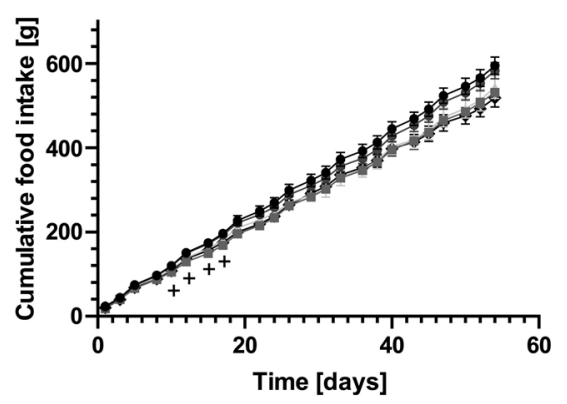

\begin{tabular}{ll|}
$\rightarrow-$ ob/ob saline & $\rightarrow$ ob/ob leptin+palm ${ }^{11}$-PrRP31 \\
$\rightarrow$ ob/ob leptin & $\rightarrow$ WT saline \\
$\rightarrow-$ ob/ob palm & 11 -PrRP31
\end{tabular}

D

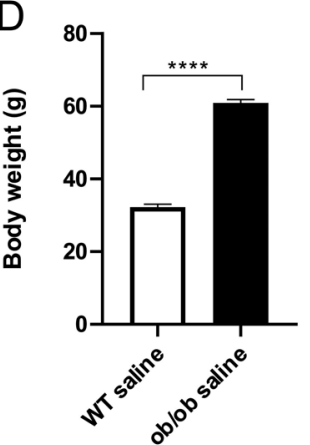

B

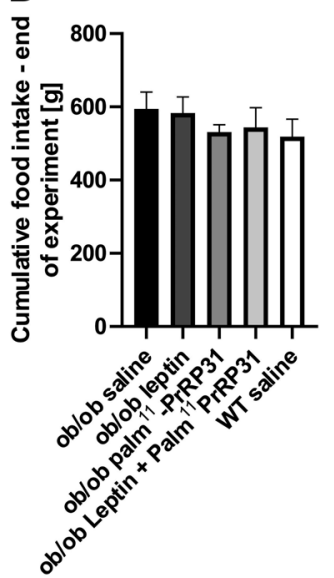

C

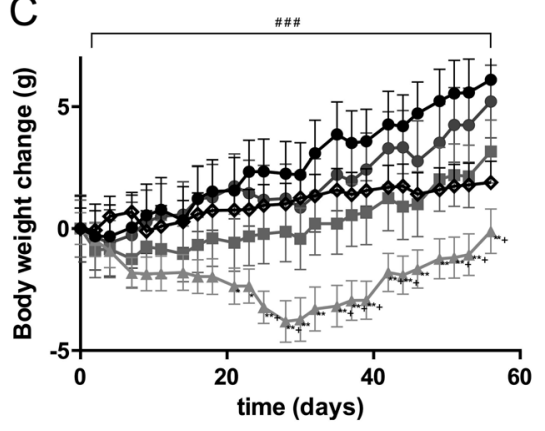

- ob/obleptin

-2-ob/ob palm ${ }^{11}$-PrRP31

- ob/ob leptin + palm ${ }^{11}$-PrRP31

^ WT saline

\section{Figure 5}

Food intake and body weight change of ob/ob mice in Experiment 2. (A) Food intake and cumulative food intake at the end of experiment of ob/ob mice treated with saline, leptin, palm ${ }^{11}$-PrRP31 and leptin + palm11-PrRP31. (B) Body weight change of ob/ob mice treated with saline, leptin, palm ${ }^{11-P r R P 31}$ and leptin + palm11-PrRP31. (C) Body weight at the end of experiment of WT saline and ob/ob saline mice. (D) Body weight at the end of experiment of ob/ob mice treated with saline, leptin, palm ${ }^{11}$-PrRP31 and leptin + palm ${ }^{11}$-PrRP31. Data are means \pm S.E.M. $(n=8-10)$. Significance is ${ }^{* /+} P<0.05, \star \star /++P<0.01$, $\star \star \star \star /++++P<0.0001$ vs ob/ob saline or ob/ob leptin group, respectively ( $t$-test or one-way ANOVA + Bonferroni post hoc test).

Ucp-1 mRNA expression was determined in Experiment 2, and there were only significant differences between phenotypes ( $o b / o b$ saline versus WT saline), but the treatment did not cause any significant change compared to $o b / o b$ saline (Supplementary Fig. 3B).

\section{Leptin and palm 11 -PrRP31 synergistically attenuated SOCS3, and both leptin and palm¹1-PrRP31 lowered AMPK phosphorylation in the hypothalami of ob/ ob mice}

Activation of the anorexigenic hypothalamic pathways JAK-STAT and AMPK was followed after treatment with leptin, palm11_PrRP31, and their combination and compared to $o b / o b$ saline group (Fig. 7A). STAT3 protein was enhanced after leptin treatment in $o b / o b$ mice (Fig. 7D); Tyr705 p-STAT did not differ significantly between saline and compound-treated $o b / o b$ groups (Fig. 6B), but Ser727 p-STAT was increased by all three treatments (Fig. 7C). SOCS3 protein, which negatively regulates leptin receptor signaling, was significantly lowered by palm11-PrRP31 and leptin + palm ${ }^{11}$-PrRP31 combination treatment, but not by leptin; this finding could point to leptin + palm ${ }^{11}$-PrRP31 synergistically attenuating the effect of SOCS3 production (Fig. 7E).

Regarding the common leptin and insulin pathway, PI3K protein was increased significantly by palm ${ }^{11}$-PrRP31 but not by single leptin or its combination with palm11. PrRP31 in $o b / o b$ mice (Fig. 7F); phosphorylation of AKT at Ser473 was not affected significantly by any treatment and only tended to increase (Fig. 7G).

AMPK phosphorylation was significantly lowered after all three treatments (Fig. 7I). 
Table 2 Morphometric and metabolic parameters Experiment 2.

\begin{tabular}{|c|c|c|c|c|c|}
\hline & WT saline & ob/ob saline & ob/ob leptin & ob/ob palm11-PrRP & ob/ob leptin+palm11-PrRP \\
\hline \multicolumn{6}{|c|}{ (A) Morphometric parameters } \\
\hline BW (g) & $32.23 \pm 0.80 * * * *$ & $60.90 \pm 0.93$ & $60.36 \pm 1.18$ & $58.15 \pm 0.87$ & $56.36 \pm 1.16 *$ \\
\hline SCAT (g) & $0.39 \pm 0.06 * * \star *$ & $6.45 \pm 0.33$ & $6.23 \pm 0.24$ & $5.57 \pm 0.31$ & $5.19 \pm 0.36 *$ \\
\hline IPAT $(g)$ & $0.49 \pm 0.05^{* * * *}$ & $1.98 \pm 0.06$ & $1.99 \pm 0.13$ & $2.37 \pm 0.16$ & $2.31 \pm 0.13$ \\
\hline Liver weight (g) & $1.35 \pm 0.04 * * * *$ & $4.42 \pm 0.14$ & $4.35 \pm 0.20$ & $3.93 \pm 0.06$ & $4.08 \pm 0.18$ \\
\hline Rectal temp $\left({ }^{\circ} \mathrm{C}\right)$ & $37.84 \pm 0.17 * * \star \star$ & $35.42 \pm 0.18$ & $35.09 \pm 0.26$ & $34.93 \pm 0.32$ & $36.52 \pm 0.14^{*}$ \\
\hline \multicolumn{6}{|c|}{ (B) Metabolic parameters } \\
\hline $\begin{array}{l}\text { Glucose } \\
(\mathrm{mmol} / \mathrm{l})\end{array}$ & $8.05 \pm 0.27$ & $7.96 \pm 0.38$ & $6.78 \pm 0.49$ & $8.29 \pm 0.40$ & $8.99 \pm 0.97$ \\
\hline $\begin{array}{l}\mathrm{Hb} 1 \mathrm{Ac}(\mathrm{mmol} / \\
\mathrm{mol})\end{array}$ & $23.8 \pm 0.36 * * \star \star$ & $33.2 \pm 1.28$ & $35.5 \pm 1.09$ & $32 \pm 2.04$ & $28.1 \pm 2.18$ \\
\hline Insulin (ng/ml) & $0.11 \pm 0.04 * * *$ & $9.43 \pm 1.78$ & $9.90 \pm 2.82$ & $16.77 \pm 4.98$ & $9.74 \pm 3.74$ \\
\hline $\mathrm{CHOL}(\mathrm{mmol} / \mathrm{l})$ & $1.75 \pm 0.07 * * \star *$ & $5.00 \pm 0.24$ & $4.50 \pm 0.17$ & $3.66 \pm 0.22 * * *$ & $3.82 \pm 0.18 * *$ \\
\hline TAG $(\mathrm{mmol} / \mathrm{l})$ & $0.9 \pm 0.09$ & $0.82 \pm 0.03$ & $0.98 \pm 0.05^{*}$ & $0.82 \pm 0.04$ & $0.83 \pm 0.04$ \\
\hline FFA (mmol/l) & $1.33 \pm 0.08$ & $1.42 \pm 0.06$ & $1.59 \pm 0.11$ & $1.64 \pm 0.10$ & $1.59 \pm 0.12$ \\
\hline
\end{tabular}

(A) Morphometric parameters of WT saline and ob/ob mice treated with saline, leptin, palm¹1-PrRP31 and leptin + palm ${ }^{11}$-PrRP31. (B) Metabolic parameters of WT saline and ob/ob mice treated with saline, leptin, palm ${ }^{11}$-PrRP31 and leptin + palm ${ }^{11}$-PrRP31. Data are means \pm S.E.M. $(n=8-10)$. Significance is $* P<0.05$, $\star * P<0.01, * * * P<0.001, * \star * \star P<0.0001$ vs ob/ob saline (t-test or one-way ANOVA + Bonferroni post hoc test).

\section{Discussion}

Leptin and PrRP were shown to cooperate in decreasing food intake and increasing energy expenditure in rodents after their central administration (Ellacott et al. 2002). In our previous studies, lipidized PrRP analogs were described to attenuate obesity and beneficially affect related metabolic disturbances in mice with diet-induced obesity (Maletinska et al. 2015, Holubova et al. 2018) and improve tolerance to glucose in Zucker diabetic (ZDF) rats and Koletsky spontaneously hypertensive obese rats (SHROB) with impaired leptin signaling (Holubova et al. 2016, Mikulaskova et al. 2018). This study aimed to further elucidate the role of leptin and PrRP in energy metabolism and to identify possible molecular mechanisms underlying these effects.

Two experiments with leptin, palm ${ }^{11}$-PrRP31, and leptin + palm ${ }^{11}$-PrRP31 combined with two treatment periods ( 2 and 8 weeks) were performed in $o b / o b$ mice at two ages: a younger one (8-10 weeks), which is metabolically active, and an older one (16-24 weeks), with established morbid obesity. The morphometric and metabolic parameters of single leptin at a subthreshold dose, single palm ${ }^{11}$-PrRP31, and their combination at the end of both experiments were studied for their potential synergistic effect as well as an evaluation of the impact of both treatments on lipid metabolism and of the longer treatment on the main signaling pathways of leptin. At two ages, $o b / o b$ mice differed in metabolic parameters and their susceptibility to treatment.

As hypothesized, in both experiments, food intake and body weight were negatively affected by both leptin and palm ${ }^{11}$-PrRP31, but the body weight change was significantly lowered only after combined leptin + palm ${ }^{11}$. PrRP31 treatment. This indicates an anorexigenic synergistic effect of leptin and palm ${ }^{11}$-PrRP31 on body weight in $o b / o b$ mice and a possible influence of this combination on the metabolic state and signaling pathways.

As $o b / o b$ mice are known to be hypothermic (Ohtake et al. 1977), both in younger and older age (Gratuze et al. 2017), body temperature was also followed at the end of both experiments. $\mathrm{Ob} / \mathrm{ob}$ mice were hypothermic compared to WT mice in both experiments, but only in older mice did the leptin+palm ${ }^{11}$-PrRP31 combination significantly upregulate the body temperature of $o b / o b$ mice, indicating their synergistic action.

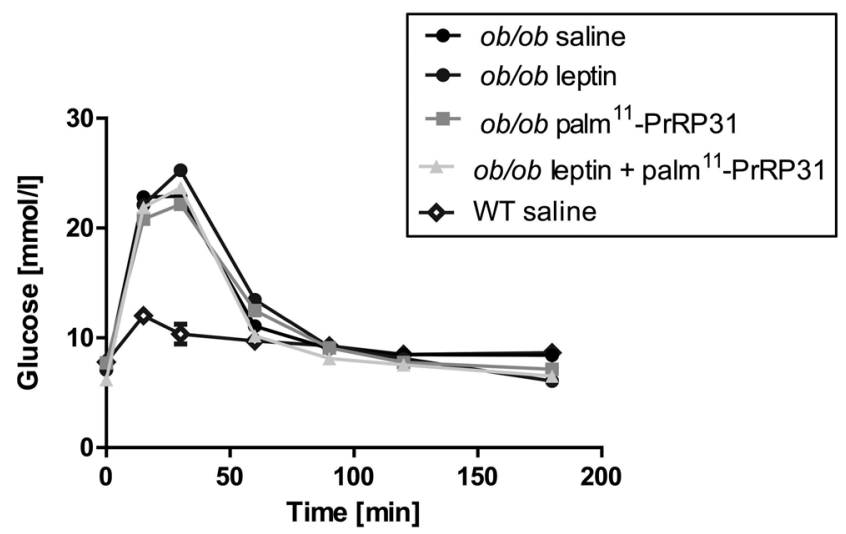

Figure 6

Oral glucose tolerance test in Experiment 2. WT mice were treated with saline and ob/ob mice were treated with saline, leptin, palm ${ }^{11}$-PrRP31 and leptin + palm ${ }^{11}$-PrRP31. Blood glucose was measured after oral glucose load 2 weeks before the end of treatment. Data are means \pm S.E.M. $(n=8-10)$ (Two-way ANOVA + Bonferroni post hoc test). 
A

\begin{tabular}{|c|c|c|c|c|c|}
\hline & $o b / o b$ saline & ob/ob leptin & $\begin{array}{l}o b / o b \\
\text { palm }{ }^{11} \text {-PrRP31 }\end{array}$ & $\begin{array}{l}\text { ob/ob leptint } \\
\text { palm }{ }^{11} \text {-PrRP31 }\end{array}$ & kDa \\
\hline p-STAT3 Y705 & $z=0 ;$ & $z=8$ & 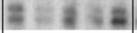 & 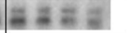 & 79,86 \\
\hline p-STAT3 5727 & $n=m-2$ & 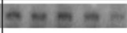 & $-m=\dot{m}=$ & $E=-2$ & 79,86 \\
\hline STAT3 & ----- & -----0 & $--m--$ & --- & 79,86 \\
\hline socs3 & 0000 & $\bullet$ & $-\infty-\infty$ & $-\cdots+\cdots$ & 26 \\
\hline PI3K & ------ & ----0 & $-0--\infty$ & $-\infty-\infty$ & 85 \\
\hline p-Akt S473 & $+-\infty-\infty$ & ---- & $--\cdots-\cdots$ & --- & 60 \\
\hline Akt & $-\infty-\infty$ & $=-\infty-\infty$ & $-0--0$ & $0-00$ & 60 \\
\hline p-AMPK & -0.00 & $-0-\infty$ & - & $-\cdots$ & 62 \\
\hline AMPK & $-\infty-\infty$ & $-\bullet \bullet \bullet-$ & $-\infty+\infty$ & $-0=-$ & 62 \\
\hline$\beta$-actin & $-\infty$ & -0.- & $-0-\infty$ & $-\infty-\infty$ & 42 \\
\hline
\end{tabular}

$B$

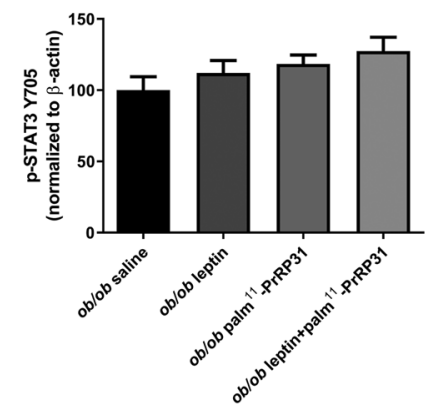

C

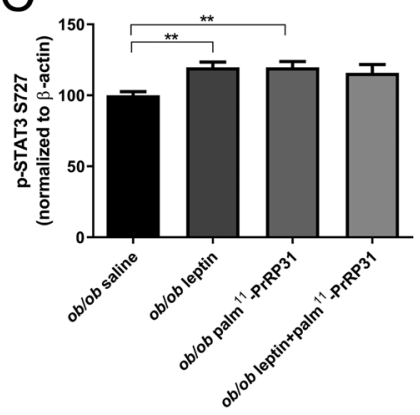

G

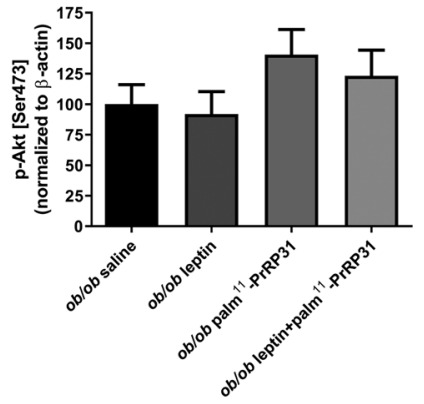

D

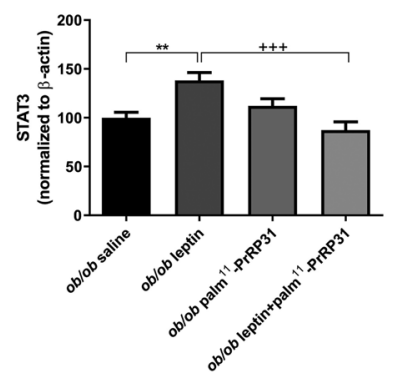

$\mathrm{H}$

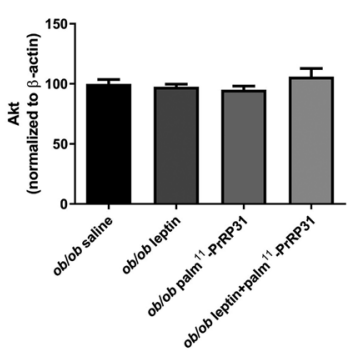

$E$

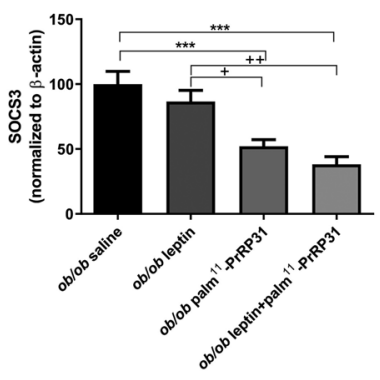

I

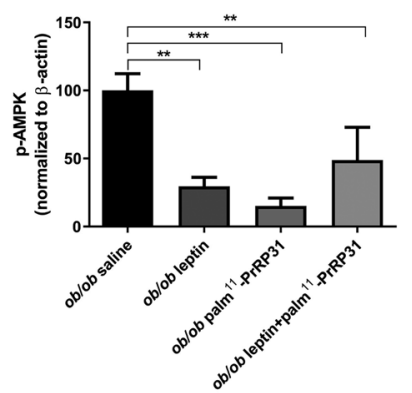

$\mathrm{F}$

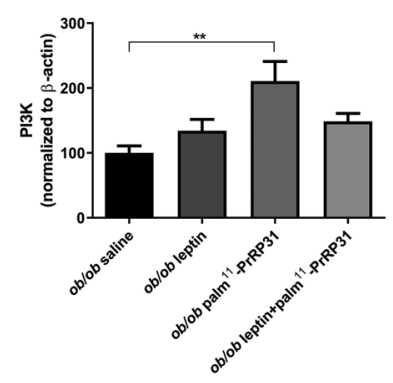

$J$

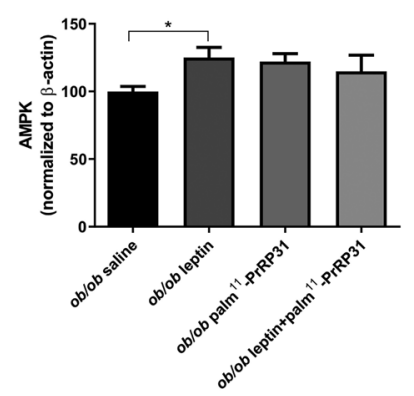

Figure 7

Hypothalamic signalling in Experiment 2. Western blot analyses in hypothalami of ob/ob mice treated with saline, leptin, palm ${ }^{11-P r R P 31}$ and leptin + palm11-PrRP31. (A) Overview of Western blots for specific proteins. (B) p-STAT3 (Y705). (C) p-STAT3 (S727). (D) STAT3. (E) SOCS3. (F) PI3K. (G) p-AKT (S473). (H) AKT. (I) p-AMPK. (J) AMPK. Data are means \pm S.E.M. $(n=8-10)$. Significance is $* /+P<0.05, * \star /++P<0.01, * \star * /+++P<0.001 \mathrm{vs}$ ob/ob saline or ob/ob leptin group, respectively (one-way ANOVA + Bonferroni post hoc test).

Hyperglycemia was reported in $o b / o b$ mice a long time ago (Enser 1972), and later on, it was specifically found only between 5 and 16 weeks of age (Menahan 1983). Moreover, $o b / o b$ mice at 26 weeks old were found to be normoglycemic compared to both WT and $o b+$ controls (Gratuze et al. 2017). In this study, $o b / o b$ saline mice aged 10 weeks were hyperglycemic; 2 weeks of treatment with leptin, palm ${ }^{11}$-PrRP31 and their combination attenuated blood glucose significantly. On the other hand, at 16 weeks of age (start of Experiment 2), all $o b / o b$ mice were normoglycemic, and no treatment affected blood glucose. However, the HbA1c level, which is considered a long-term measure of glucose control (Sacks 2013), was significantly higher in the older $o b / o b$ saline than in WT saline and was not affected by any treatment. In addition, the OGTT demonstrated impaired glucose tolerance in older $o b / o b$ mice when compared to WT saline and was not affected by any treatment. Similarly, a glucose tolerance test after an intraperitoneal glucose load showed impaired glucose tolerance in $o b / o b$ mice at 26 weeks old (Gratuze et al. 2017). This suggests that even though $o b / o b$ mice at the older age of 24 weeks were normoglycemic, their regulation of blood glucose was impaired.

A significantly enhanced insulin level in $o b / o b$ mice at 8 and 16 weeks of age was reported a long time ago (Beloff-Chain et al. 1975), and $o b / o b$ mice were found 
to be hyperinsulinemic until 63 weeks of age (Menahan 1983). Similarly, in this study, $o b / o b$ mice aged 10,16 , and 24 weeks had hyperinsulinemia that was resistant to any treatment. Likewise, hyperinsulinemia and an enhanced HOMA index were reported at 4 weeks and then at 26 weeks of age in $o b / o b$ mice (Gratuze et al. 2017).

Increased cholesterol but similar TAG levels in $o b / o b$ mice compared to WT mice were also reported a while ago (Enser 1972). Similarly, in this study, cholesterol levels were found to be significantly increased in $o b / o b$ mice at the ages of 10,16 , and 24 weeks compared to their respective WT controls. Two-week-long treatment did not affect cholesterol levels in younger $o b / o b$ mice, but an 8-week-long intervention with palm ${ }^{11}$-PrRP31 and its combination with leptin attenuated cholesterol levels in 24-week-old $o b / o b$ mice very significantly. Analogously to Enser et al. (1972), the TAG level did not differ between the $o b / o b$ saline and WT saline at 10,16, and 24 weeks of age and was not affected by any treatment.

As liver weight was significantly higher in 10-week-old $o b / o b$ saline compared to WT saline and was attenuated by all treatments and histological images of liver steatosis followed this pattern in Experiment 1, an effect of treatment on liver lipid metabolism came into question. Similarly, the increased liver weight of 14 -week-old $o b / o b$ mice was linked to de novo lipogenesis (Perfield et al. 2013). In this study, $o b / o b$ controls aged 10 weeks showed increased hepatic de novo lipogenesis through Acaca and Fasn mRNA expression compared to WT controls that was attenuated by treatment with the leptin + palm ${ }^{11}$-PrRP31 combination. Lipid oxidation as evaluated through mRNA expression of Cpt1a and Pck1, which catalyze fatty acid oxidation, was enhanced in $o b / o b$ saline compared to WT saline but remained unaffected by any treatment. In $o b / o b$ mice, the leptin + palm ${ }^{11}$-PrRP31 combination also lowered hepatic synthesis of glucose, the main substrate for lipogenesis, through attenuation of G6pc mRNA, a key enzyme catalyzing gluconeogenesis and glycogenolysis. Although liver weight was also significantly higher at 16 and 24 weeks of age in $o b / o b$ mice compared to WT mice in Experiment 2, no differences between $o b / o b$ saline and WT saline in liver mRNA expression of genes regulating lipid metabolism were registered, and no effect of the treatment was found. This could be explained by a gradual decrease in hepatic fatty acid synthesis from 7 to 16 weeks of age in $o b / o b$ mice (Kaplan \& Leveille 1981). Rodriguez et al. (2015) found mRNA expression of aquaglyceroporin 9 (AQP9), the channel for glycerol influx into liver, to be positively correlated with hepatic steatosis in ob/ob mice.
It points to glycerol abundance as another driving force of liver steatosis, besides de novo lipogenesis.

Lipidized PrRP was shown to target and activate the PVN, DMN, arcuate nucleus, and lateral hypothalamic area (Maletinska et al. 2015, Pirnik et al. 2015), and PI3K activation was detected after sub chronic palm ${ }^{11}$-PrRP31 administration in the hypothalamus (Holubova et al. 2018). In this study, two main anorexigenic hypothalamic leptin pathways, JAK-STAT and AMPK, were followed in hypothalami from Experiment 2, where body weight change after leptin+palm ${ }^{11}$-PrRP31 treatment was significant compared to $o b / o b$ saline and single leptin. Regarding JAK/STAT, phosphorylation of STAT3 was found to be increased only at Ser727 but not at Tyr705 after treatment with leptin, palm ${ }^{11}$-PrRP31, and the leptin-palm ${ }^{11}$-PrRP31 combination. Although Tyr705 is considered the primary phosphorylation epitope in STAT3, direct Ser727 phosphorylation by insulin and other ligands was reported (Zhang et al. 2001). Positively regulated STAT3 and downregulated SOCS3 at the same time suggested that both leptin and palm ${ }^{11}$-PrRP31 support JAK/STAT signaling in the hypothalami of $o b / o b$ mice.

Hypothalamic AMPK phosphorylation was significantly lowered after all three treatments. This finding suggests that the AMPK anorexigenic pathway in the hypothalami of $o b / o b$ mice was restored not only by leptin supplementation but also by palm ${ }^{11}$-PrRP31 treatment. As inhibition of hypothalamic AMPK activity is necessary for the anorexigenic effects of leptin (Minokoshi et al. 2004), this study suggests that palm ${ }^{11}$-PrRP31 could compensate for deficient leptin in $o b / o b$ mice regarding leptin anorexigenic action in the hypothalamus. Moreover, a significant decrease in SOCS3 by palm ${ }^{11-P r R P 31}$ was not reached by a subthreshold dose of single leptin but by the leptin + palm ${ }^{11}$-PrRP31 combination.

The synergistic effect of leptin and palm ${ }^{11}$-PrRP31 was proven by several parameters: the decrease in liver weight and glucose levels after a shorter treatment in younger mice, and the body weight change, increase in body temperature, lowered cholesterol level and SOCS3 production with a longer treatment of older mice.

In conclusion, leptin and palm ${ }^{11}$-PrRP31 synergistically lowered body weight and synergistically increased body temperature in older $o b / o b$ mice with established morbid obesity. Regarding PrRP, this finding is novel and could point to other potent beneficial PrRP effects in the brain as obesity and hypothermia were recently linked to neurodegeneration. 


\section{Supplementary materials}

This is linked to the online version of the paper at https://doi.org/10.1530/ JME-19-0188.

\section{Declaration of interest}

The authors declare that there is no conflict of interest that could be perceived as prejudicing the impartiality of the research reported.

\section{Funding}

This work was supported by GA CR grant No. 18-10591S, RVO:61388963 of AS CR and RVO:67985823 of AS CR.

\section{Acknowledgements}

The authors would like to thank $\mathrm{H}$ Vysušilová for excellent technical assistance, and M Blechová for synthesis of PrRP analog.

\section{References}

Beloff-Chain A, Freund N \& Rookledge KA 1975 Blood glucose and serum insulin levels in lean and genetically obese mice. Hormone and Metabolic Research 7 374-378. (https://doi. org/10.1055/s-0028-1093730)

Dodd GT \& Luckman SM 2013 Physiological roles of GPR10 and PrRP signaling. Frontiers in Endocrinology 4 20. (https://doi.org/10.3389/ fendo.2013.00020)

Ellacott KL, Lawrence CB, Rothwell NJ \& Luckman SM 2002 PRLreleasing peptide interacts with leptin to reduce food intake and body weight. Endocrinology 143 368-374. (https://doi.org/10.1210/ endo.143.2.8608)

Enser M 1972 Clearing-factor lipase in obese hyperglycaemic mice (obob). Biochemical Journal 129 447-453. (https://doi.org/10.1042/ bj1290447)

Garfield AS, Patterson C, Skora S, Gribble FM, Reimann F, Evans ML, Myers Jr MG \& Heisler LK 2012 Neurochemical characterization of body weight-regulating leptin receptor neurons in the nucleus of the solitary tract. Endocrinology 153 4600-4607. (https://doi.org/10.1210/ en.2012-1282)

Gratuze M, El Khoury NB, Turgeon A, Julien C, Marcouiller F, Morin F, Whittington RA, Marette A, Calon F \& Planel E 2017 Tau hyperphosphorylation in the brain of ob/ob mice is due to hypothermia: importance of thermoregulation in linking diabetes and Alzheimer's disease. Neurobiology of Disease 98 1-8. (https://doi. org/10.1016/j.nbd.2016.10.004)

Hardie DG 2008 AMPK: a key regulator of energy balance in the single cell and the whole organism. International Journal of Obesity $\mathbf{3 2}$ (Supplement 4) S7-S12. (https://doi.org/10.1038/ijo.2008.116)

Harris RB, Zhou J, Redmann Jr SM, Smagin GN, Smith SR, Rodgers E \& Zachwieja JJ 1998 A leptin dose-response study in obese (ob/ob) and lean (+/?) mice. Endocrinology 139 8-19. (https://doi.org/10.1210/ endo.139.1.5675)

Hinuma S, Habata Y, Fujii R, Kawamata Y, Hosoya M, Fukusumi S, Kitada C, Masuo Y, Asano T, Matsumoto H, et al. 1998 A prolactinreleasing peptide in the brain. Nature 393 272-276. (https://doi. org/10.1038/30515)

Holubova M, Zemenova J, Mikulaskova B, Panajotova V, Stohr J, Haluzik M, Kunes J, Zelezna B \& Maletinska L 2016 Palmitoylated PrRP analog decreases body weight in DIO rats but not in ZDF rats. Journal of Endocrinology 229 85-96. (https://doi.org/10.1530/JOE15-0519)
Holubova M, Hruba L, Neprasova B, Majercikova Z, Lacinova Z, Kunes J, Maletinska L \& Zelezna B 2018 Prolactin-releasing peptide improved leptin hypothalamic signaling in obese mice. Journal of Molecular Endocrinology 60 85-94. (https://doi.org/10.1530/JME-17-0171)

Kahn BB 2019 Adipose tissue, inter-organ communication, and the path to Type 2 diabetes: the 2016 Banting medal for scientific achievement lecture. Diabetes 68 3-14. (https://doi.org/10.2337/ dbi18-0035)

Kaplan ML \& Leveille GA 1981 Development of lipogenesis and insulin sensitivity in tissues of the ob/ob mouse. American Journal of Physiology 240 E101-E107. (https://doi.org/10.1152/ ajpendo.1981.240.2.E101)

Kwon O, Kim KW \& Kim MS 2016 Leptin signalling pathways in hypothalamic neurons. Cellular and Molecular Life Sciences 73 1457-1477. (https://doi.org/10.1007/s00018-016-2133-1)

Maletínská L, Maixnerová J, Matysková R, Haugvicová R, Pirník Z, Kiss A \& Zelezná B 2008 Synergistic effect of CART (cocaine- and amphetamine-regulated transcript) peptide and cholecystokinin on food intake regulation in lean mice. BMC Neuroscience 9101. (https://doi.org/10.1186/1471-2202-9-101)

Maletinska L, Nagelova V, Ticha A, Zemenova J, Pirnik Z, Holubova M, Spolcova A, Mikulaskova B, Blechova M, Sykora D, et al. 2015 Novel lipidized analogs of prolactin-releasing peptide have prolonged halflives and exert anti-obesity effects after peripheral administration. International Journal of Obesity 39 986-993. (https://doi.org/10.1038/ ijo.2015.28)

Maniscalco JW \& Rinaman L 2014 Systemic leptin dose-dependently increases STAT3 phosphorylation within hypothalamic and hindbrain nuclei. American Journal of Physiology: Regulatory, Integrative and Comparative Physiology 306 R576-R585. (https://doi.org/10.1152/ ajpregu.00017.2014)

Maruyama M, Matsumoto H, Fujiwara K, Kitada C, Hinuma S, Onda H, Fujino M \& Inoue K 1999 Immunocytochemical localization of prolactin-releasing peptide in the rat brain. Endocrinology 140 2326-2333. (https://doi.org/10.1210/endo.140.5.6685)

Matsumoto H, Murakami Y, Horikoshi Y, Noguchi J, Habata Y, Kitada C, Hinuma S, Onda H \& Fujino M 1999 Distribution and characterization of immunoreactive prolactin-releasing peptide (PrRP) in rat tissue and plasma. Biochemical and Biophysical Research Communications 257 264-268. (https://doi.org/10.1006/ bbrc.1999.0463)

Menahan LA 1983 Age-related changes in lipid and carbohydrate metabolism of the genetically obese mouse. Metabolism: Clinical and Experimental 32 172-178. (https://doi.org/10.1016/00260495(83)90225-1)

Mikulaskova B, Holubova M, Prazienkova V, Zemenova J, Hruba L, Haluzik M, Zelezna B, Kunes J \& Maletinska L 2018 Lipidized prolactin-releasing peptide improved glucose tolerance in metabolic syndrome: Koletsky and spontaneously hypertensive rat study. Nutrition and Diabetes 8 5. (https://doi.org/10.1038/s41387-017-0015-8)

Minokoshi Y, Alquier T, Furukawa N, Kim YB, Lee A, Xue B, Mu J, Foufelle F, Ferre P, Birnbaum MJ, et al. 2004 AMP-kinase regulates food intake by responding to hormonal and nutrient signals in the hypothalamus. Nature 428 569-574. (https://doi.org/10.1038/ nature02440)

Ohtake M, Bray GA \& Azukizawa M 1977 Studies on hypothermia and thyroid function in the obese (ob/ob) mouse. American Journal of Physiology 233 R110-R115. (https://doi.org/10.1152/ ajpregu.1977.233.3.R110)

Perfield 2nd JW, Ortinau LC, Pickering RT, Ruebel ML, Meers GM \& Rector RS 2013 Altered hepatic lipid metabolism contributes to nonalcoholic fatty liver disease in leptin-deficient $\mathrm{Ob} / \mathrm{Ob}$ mice. Journal of Obesity 2013 296537. (https://doi. org/10.1155/2013/296537)

Pirnik Z, Zelezna B, Kiss A \& Maletinska L 2015 Peripheral administration of palmitoylated prolactin-releasing peptide induces (c) 2020 Society for Endocrinology Published by Bioscientifica Ltd. Printed in Great Britain 
Fos expression in hypothalamic neurons involved in energy homeostasis in NMRI male mice. Brain Research 1625 151-158. (https://doi.org/10.1016/j.brainres.2015.08.042)

Prazienkova V, Holubova M, Pelantova H, Buganova M, Pirnik Z, Mikulaskova B, Popelova A, Blechova M, Haluzik M, Zelezna B, et al. 2017 Impact of novel palmitoylated prolactin-releasing peptide analogs on metabolic changes in mice with diet-induced obesity. PLoS ONE 12 e0183449. (https://doi.org/10.1371/journal.pone.0183449)

Rodriguez A, Moreno NR, Balaguer I, Mendez-Gimenez L, Becerril S, Catalan V, Gomez-Ambrosi J, Portincasa P, Calamita G, Soveral G, et al. 2015 Leptin administration restores the altered adipose and hepatic expression of aquaglyceroporins improving the nonalcoholic fatty liver of ob/ob mice. Scientific Reports 5 12067. (https:// doi.org/10.1038/srep12067)

Sacks DB 2013 Hemoglobin A1c in diabetes: panacea or pointless? Diabetes 62 41-43. (https://doi.org/10.2337/db12-1485)

Schwartz MW, Seeley RJ, Campfield LA, Burn P \& Baskin DG 1996 Identification of targets of leptin action in rat hypothalamus. Journal of Clinical Investigation 98 1101-1106. (https://doi.org/10.1172/ JCI118891)

Špolcová A, Mikulášková B, Holubová M, Nagelová V, Pirnik Z, Zemenová J, Haluzík M, Železná B, Galas MC \& Maletínská L 2015
Anorexigenic lipopeptides ameliorate central insulin signaling and attenuate tau phosphorylation in hippocampi of mice with monosodium glutamate-induced obesity. Journal of Alzheimer's Disease 45 823-835. (https://doi.org/10.3233/JAD-143150)

Takayanagi Y, Matsumoto H, Nakata M, Mera T, Fukusumi S, Hinuma S, Ueta Y, Yada T, Leng G \& Onaka T 2008 Endogenous prolactinreleasing peptide regulates food intake in rodents. Journal of Clinical Investigation 118 4014-4024. (https://doi.org/10.1172/JCI34682)

Unger RH, Zhou YT \& Orci L 1999 Regulation of fatty acid homeostasis in cells: novel role of leptin. PNAS 96 2327-2332. (https://doi. org/10.1073/pnas.96.5.2327)

Vaisse C, Halaas JL, Horvath CM, Darnell Jr JE, Stoffel M \& Friedman JM 1996 Leptin activation of Stat3 in the hypothalamus of wild-type and ob/ob mice but not db/db mice. Nature Genetics 14 95-97. (https://doi.org/10.1038/ng0996-95)

Zhang Y, Proenca R, Maffei M, Barone M, Leopold L \& Friedman JM 1994 Positional cloning of the mouse obese gene and its human homologue. Nature 372 425-432. (https://doi.org/10.1038/372425a0)

Zhang Y, Liu G \& Dong Z 2001 MSK1 and JNKs mediate phosphorylation of STAT3 in UVA-irradiated mouse epidermal JB6 cells. Journal of Biological Chemistry 276 42534-42542. (https://doi. org/10.1074/jbc.M106044200)

Received in final form 6 December 2019

Accepted 12 December 2019

Accepted Manuscript published online 17 December 2019
(C) 2020 Society for Endocrinology Published by Bioscientifica Ltd. Printed in Great Britain 